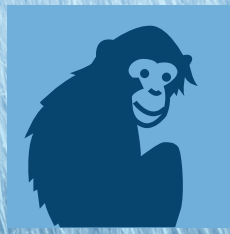

\title{
animals
}

an Open Access Journal by MDPI

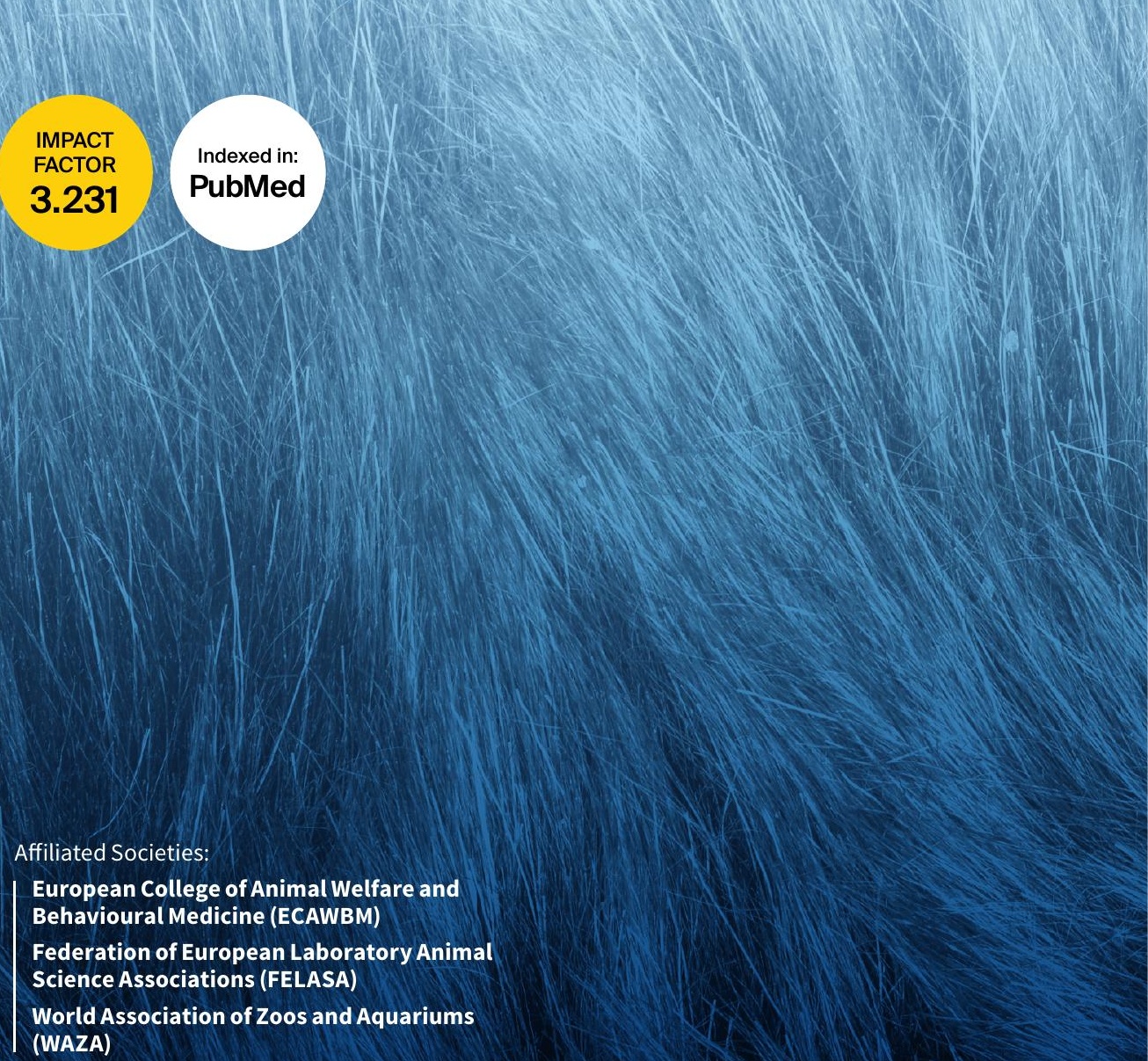

(WAZA)

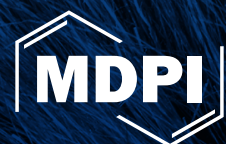




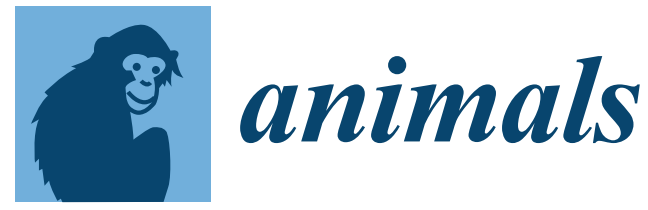

an Open Access Journal by MDPI

Editor-in-Chief

Prof. Dr. Clive J. C. Phillips

Deputy Editors-in-Chief

Dr. Gareth Pearce

Dr. Mandy Paterson

Prof. Dr. Marina Von Keyserlingk

\section{Message from the Editor-in-Chief}

Animals is an on-line open access journal that was first published in 2011. Animals adheres to rigorous peerreview and editorial processes and publishes only high quality manuscripts that address important issues in the many varied disciplines that involve animals, with a focus on animal science, animal welfare and animal ethics. Animals is covered in the Science Citation Index Expanded (SCIE) in Web of Science, with the latest Impact Factor: 3.231 (2021, ranks 13 /62 (Q1) in 'Agriculture, Dairy \& Animal Science'; 16/144 (Q1) in 'Veterinary Sciences'), 5-Year Impact Factor: 3.312.

\section{Author Benefits}

Open Access Unlimited and free access for readers

C No Copyright Constraints Retain copyright of your work and free use of your article

IF 2021 Impact Factor: 3.231 (Journal Citation Reports - Clarivate, 2022)

S Discounts on Article Processing Charges (APC) If you belong to an institute that participates with the MDPI Institutional Open Access Program

ป No Space Constraints, No Extra Space or Color Charges No restriction on the length of the papers, number of figures or colors

Journal Rank JCR - Q1 (Veterinary Sciences) / CiteScore - Q1 (General Veterinary)

Coverage by Leading Indexing Services Scopus, SCIE (Web of Science), PubMed, PMC, Embase, PubAg, AGRIS, Animal Science Database, CAB Abstracts, and other databases

( Rapid Publication First decision provided to authors approximately 17 days after submission; acceptance to publication is undertaken in 2.8 days (median values for papers published in this journal in the second half of 2022) 


\section{IMPACT

\section{Aims and Scope}

Animals (ISSN 2076-2615) publishes original research articles, reviews, communications, and short notes that are relevant to any field of study that involves animals, including animal science, animal welfare, animal ethics, zoology, ethnozoology, and anthrozoology. Our aim is to encourage scientists to publish their experimental and theoretical research in as much detail as possible. Full experimental details and/ or method of study, necessary ethical approval must be provided for research articles.

The Primary Areas of Animals include:

Animal science

Human and animal interactions

Animal management and welfare science

Animals and society

\section{Editorial Office}

Animals Editorial Office animals@mdpi.com MDPI, St. Alban-Anlage 66 4052 Basel, Switzerland Tel: +41616837734 www.mdpi.com mdpi.com/journal/animals 
MDPI is a member of

PASPA

The Association of

Learned \& Professional

Society Publishers
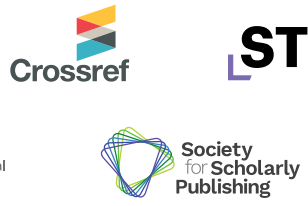

STM'

$|\mathbf{C}| \mathbf{O}|\mathbf{P}|$

SPARC $*$

Europe

\title{
Affiliated Societies
}

Animal Welfare and Behavioural Medicine

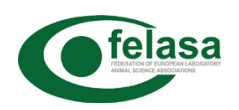

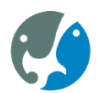

WAZA

World Association

\section{Follow}

\author{
f facebook.com/MDPIOpenAccessPublishing \\ 3. twitter.com/MDPIOpenAccess \\ in linkedin.com/company/mdpi \\ (O) instagram.com/mdpiopenaccess \\ $\boldsymbol{6}^{\text {") }}$ weibo.com/mdpicn \\ (i) Wechat:MDPI-China
}

\section{Subscribe}

blog.mdpi.com 